\title{
Assessment of the ecological state of the surface waters of the Nikitinsky fish passage channel during dredging work
}

\author{
Sergey Strelkov ${ }^{1 *}$, Ludmila Boronina ${ }^{1}$, Andrey Sorokin ${ }^{2}$, Kirill Kondrashin ${ }^{1}$, and Roman \\ Petrov ${ }^{2}$. \\ 1 Astrakhan state University of Architecture and civil Engineering, 414056, 18 Tatishcheva, \\ Astrakhan, Russia \\ ${ }^{2}$ Astrakhan State University, 414056, 20A Tatishcheva, Astrakhan, Russia
}

\begin{abstract}
Fish passage channels along the main delta watercourses serve for upstream spawning of fish and stingrays of young and adult fish back to sea, thereby preserving and multiplying the biodiversity of the ecosystems of the Caspian basin. The flickering sections of the canal-fish passage require periodic dredging. When analyzing the ecological and geochemical situation of the territory, one of the most informative objects of research is surface water. Accumulating pollutants coming from watersheds over a long period of time, soils are an indicator of the ecological condition of the territory, a kind of integral indicator of the level of pollution. As part of the study, an assessment was made of the ecotoxicological state of the surface waters of the fish passage channel during dredging in the Volga delta, the environmental toxicological status of the coastal zone of the canal was analyzed according to accepted standards, possible adverse environmental changes were predicted, and proposals were developed for a program of production ecological monitoring the nature of changes in surface water quality as a major component of the ecosystem.
\end{abstract}

\section{Introduction}

\begin{abstract}
At present, the problems of studying the impact of anthropogenic activities on the ecological condition and qualitative characteristics of surface waters of large and small rivers are becoming quite relevant against the background of increasing economic use. Studies are carried out using various methods (assessment of water quality based on the results of chemical analysis, calculation of the integral indicator of water quality - water pollution index (WPI), as well as using the method of phytotesting) [1, 2, 3]. Particular attention is paid to bioindexing and biotesting $[4,5,6]$.

It has been established that the Russian sanitary and hygienic standards do not provide for the ecological well-being of aquatic ecosystems, which degrade and lose their resource
\end{abstract}

\footnotetext{
*Corresponding author: ast_strelkov@mail.ru
} 
value, which causes problems in all areas of water use. To ensure the eco-safety of surface waters, it is necessary to take an ecosystem approach and to develop regional standards on the ecological limitation criteria of harmfulness in accordance with the recommendations of the WFD adopted in the EU [7].

Pollution of surface water bodies begins with the release of various pollutants into the waters of rivers, lakes and groundwater. In most cases, the pollution of water bodies remains invisible, as the pollutants are dissolved in the water [8].

When dredging in the water using dredging equipment, the main negative impact on the water body is associated with the formation of wastewater on the vessels of the dredging and auxiliary fleets and their discharge into the water area and clouding of the aquatic environment as a result of the transition of the finely dispersed part of bottom sediments into suspension when developing and storing the extracted soil in an underwater dump. In the process of dredging and auxiliary smelting equipment functioning, domestic and industrial (bilge) wastewaters are formed. The formation of domestic wastewater is associated with the water consumption of ship crews, the formation of bilge water - with the operation of ship power plants. In modern conditions, most of the canal-fish passages of the Volga River delta and the Northern Caspian region have not lost their fishery significance. However, an increase in the level of the Caspian Sea has significantly reduced their length [9]. Carrying out monitoring of water bodies leads to a significant accumulation of data, allowing to assess and characterize the state of the reservoir, to localize places of technogenic pressure on its water area. Currently, an increasing number of researchers use the data on the degree of pollution of the aquatic environment and the level of toxicant accumulation in bottom sediments (BS) to assess the ecological state of the aquatic ecosystem [10]. The processing of data obtained as a result of monitoring bottom sediments is usually carried out in two stages: - reconnaissance assessment, where a generalized indicator is used to characterize the general condition of the ecosystem; - interpretation of the results of the content of all analyzed components. So, it is proposed to use the oxidation-reduction state of the medium as a generalized indicator of the quality of surface water, and for the sediment - the value of the oxidation-reduction potential (Eh), which correlates with the content of organic matter and gran composition of bottom sediments [11]. Quite widespread is the use of biological methods to control the quality of water bodies [12], however, their use is limited by the numerous requirements for test objects, including their genetic uniformity, high metabolic rate, the absence of seasonal changes in functional activity, and the presence of resistance to stress associated with testing procedures. Also, factors related to pollution influence the test objects to a large extent: $\mathrm{pH}$, oxygen content, temperature, illumination, salinity, etc [13]. Often, a change in one of these factors can lead to the death of the test object, which in turn can lead to incorrect assessment of the ecological status of the reservoir. The results of this study can be used in conducting a comprehensive assessment of the ecological state of the environment [14] in the Volga delta, in particular, in conducting environmental surveys to develop design documentation for bottom-dredging works on fish pass channels.

\section{Materials and methods}

Soils of the coastal strip of the Nikitinsky channel-fish passage were chosen as the object of study (Fig. 1). On this channel, at the time of conducting research and selecting soil samples, bottom-dredging works were not carried out, but only planned. However, the results of past dredging and storage of bottom material on the surface of the soil cover along the canal were visible. 


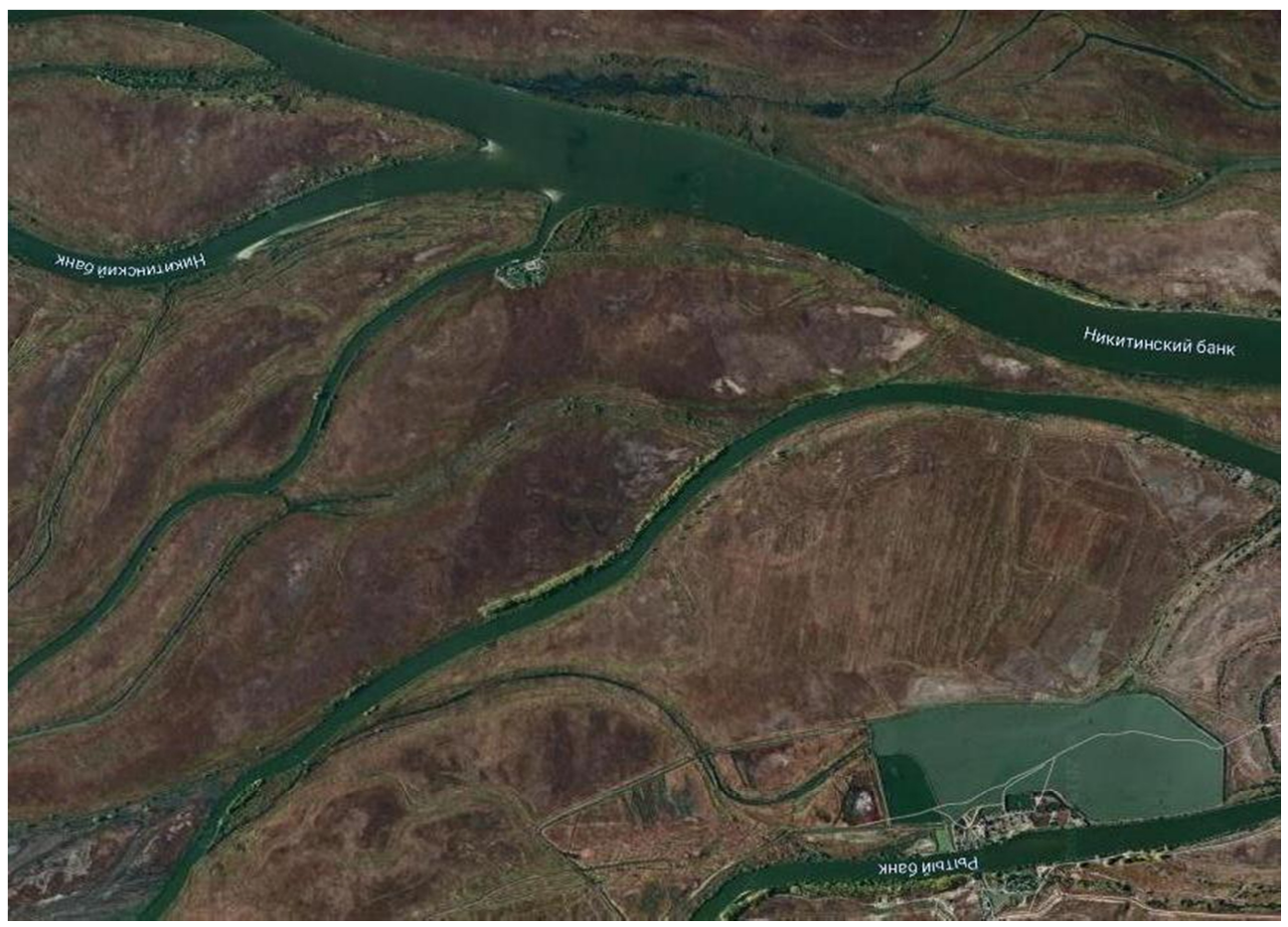

Fig. 1. Satellite image of the object of study.

Fishery channels are located in the lower part of the river delta and in the estuary. The most characteristic feature of the estuary seaside is its enormous size and exceptional shallow water. The shallow-water near-delta (avandelta) part of the estuary (shallow zone of the seaside) extending from north to south $35-50 \mathrm{~km}$ and depths of $1.5-2.5 \mathrm{~m}$ (at sea level minus $27 \mathrm{~m} \mathrm{BS}$ ) is a wide, slightly inclined towards the sea a platform. This is the flooded part of the delta, which formed at a lower standing sea level. In this shallow water, there is a slow plane runoff of the Volga waters.

Numerous shallows and islands, natural furrows and artificial navigable canals and canal-fish passages, dumps of soil along the canals, complicate the flat topography of this part of the coast.

The dredging site under consideration is located in the western part of the outpost zone of the Volga River Delta in the territory of the "Kamyzyaksky District" of the Astrakhan Region.

Fish ladder-channels extend within the lower part of the delta and Volga shallow zone before wellhead space (avandelta).

The Nikitinsky fish-channel is located in the western part of the Volga delta and takes its beginning in one of its powerful branches, the Kizan River. The date of entry of the Nikitinsky channel-fish passage January 1968, the length of $19.25 \mathrm{~km}$. Absolute marks of the bottom surface along the axis of the Nikitinsky channel are minus $26.60-30.3 \mathrm{~m}$ BS, the water horizon for the study period is from minus $27.25 \mathrm{~m} \mathrm{BS}$ to minus $27.50 \mathrm{~m} \mathrm{BS}$.

According to engineering and geological surveys, the channel part of the Nikitinsky fish passage channel, within the dredging slot, is composed of modern alluvial deposits represented by silts, sandy loam, loam, clay and sand.

The main sources of water pollution and bottom sediments are upstream settlements, motor boats and boats. 
In accordance with GOST 17.8.1.02-88 "Nature protection. Landscapes. Classification" The study area is confined to the water management landscape associated with the riverine landscape and the landscape of settlements, partially bordering the protected landscape.

When performing work, it is recommended to provide for the organization of the collection of all types of wastewater generated on the vessels of the dredging and auxiliary fleet - wastewater, waste, as well as their delivery for disposal.

When implementing this decision, the negative impact of the resulting ship-generated wastewater on the aquatic environment will be virtually eliminated.

The scale of water pollution by suspended solids is determined by the ability of the fine fractions of the extracted soil to go into suspension during dredging and dumping it into an underwater dump.

Pollution of the aquatic environment with suspended solids during dredging and dumping of soils into underwater dumps cannot be eliminated. Therefore, the formation of suspended matter in the process of working with specific soils should be normalized and damage to the aquatic environment should be determined [15].

To minimize the negative impact on the aquatic environment, it is necessary:

1. Observance of dredging production technology;

2. performance of work in periods agreed with the fish protection authorities, and in terms excluding the occurrence of emergency situations with dredging equipment according to meteorological and hydrological conditions;

3. monitoring the state of the aquatic environment (monitoring) at the work sites;

The impact of the work performed on the animal world.

The impact of dredging is temporary.

Dredging works can theoretically have a frightening effect (noise, emissions) on avifauna.

The main factor-affecting mammals may be a disturbance factor, in this case, the noise generated by technical means. Noises scare animals away from the place of production.

Storage of bottom sediments along the coastline will disrupt the current landscape, which may entail a change in vegetation cover and, in turn, reduce the habitat of animals.

The following factors may have a negative impact on the state of fish stocks:

1. death of benthic food organisms in the area of work and dumps;

2. decrease in the productivity of the food supply (plankton and benthos) in a plume of high turbidity;

3. death of plankton fodder organisms on dredger intake devices.

The impact of the work performed on the land cover.

The main consequences of a local disturbance of the vegetation cover are as follows:

1. decrease in the projective cover of the soil due to placement on the ground surfaces of bottom soils;

2. change in soil cover with a change in soil type;

3. succession of vegetation;

4. decrease in soil resistance to erosion and deflation processes.

During the implementation of the planned work performed, it is possible to change the current landscape, in particular due to the organization of landfills, the formation of new landforms and, as a result, the succession of vegetation. In addition, when storing bottom soils in flooded areas, the formation of artificial islands is possible, which thereby leads to a decrease in the habitat of aquatic vegetation.

\section{Results and discussion}

Surface water is fresh by the degree of mineralization - the value of the dry residue is 0.291 $-0.346 \mathrm{~g} / \mathrm{dm}^{3}$, according to the chemical sulfate-bicarbonate calcium. 
The reaction of the medium ranges from $\mathrm{pH} 7.4$ to 8.3 units.

The chloride content is (in four samples) $25-32 \mathrm{mg} / \mathrm{dm}^{3}$, sulfates $77-125 \mathrm{mg} / \mathrm{dm}^{3}$, sodium $23-34 \mathrm{mg} / \mathrm{dm}^{3}$.

Organoleptic indicators: smell 0 points, turbidity -0.8 in sample No. $1 ; 1.0$ in sample No. 2; 0.9 in sample No. 3 and 1.2 in sample No. 4 , color $-12^{\circ}$ in sample No. $1 ; 14^{\circ}$ in sample No. $2 ; 15^{\circ}$ in sample No. 3 and $18^{\circ}$ in sample No. 4.

The content of petroleum products is less than $0.04 \mathrm{mg} / \mathrm{dm}^{3}$, phenols $-0.001-0.004$ $\mathrm{mg} / \mathrm{dm}^{3}$, APAF - less than $0.01 \mathrm{mg} / \mathrm{dm}^{3}$.

In surface water samples, an excess of the MPC of heavy metals (according to GN 2.1.5.2280-07) was found for cadmium for all four samples.

According to the order of the Federal Agency for Fisheries of January 18, $2010 \mathrm{~N} 20$ "On the approval of water quality standards for water bodies of fishery importance, including the standards of maximum permissible concentrations of harmful substances in the waters of water bodies of fishery value", the maximum MPC for heavy metals is exceeded for samples No. 1 and No. 2 in 2.2 times, chromium in samples No. 1, No. 3, No. 4, respectively, in 1.3, 1.2 and 1.1 times, for copper in sample No. 3 in 2 times and sample No. 4 in 1.5 times, for molybdenum in sample No. 3 in 50 times, sample No. 4 in 45 times.

According to data obtained from the Astrakhan Center for Hydrometeorology and Environmental Monitoring, the background values for suspended solids are $13.09 \mathrm{mg} / \mathrm{dm}^{3}$, BOD5 - $2.83 \mathrm{mg} / \mathrm{dm}^{3}$, COD $-29.63 \mathrm{mg} / \mathrm{dm}^{3}$, iron $0.215 \mathrm{mg} / \mathrm{dm}^{3}$, total hardness -4.28 $\mathrm{mEq} / 1, \mathrm{pH}-8.4$ units, color $-43^{\circ}$, smell - 0 points.

In accordance with GOST 17.5.3.04-83, land disturbed by open pit mining (Clause 2) must be recultivated, and the fertility of farmland restored. Reclamation involves the removal of the humus horizon and its storage in a temporary dump. In this case, the fertile layer must comply with the requirements of GOST 17.4.3.02-85.

According to the soil properties of sections 1,2,4 and 6, they cannot be protected due to the low humus content and light particle size distribution.

The properties of soils of sections 3 and 5 (high humus content, low salt content) are especially protected during work performed (dredging). Soil allotment maps should be placed on sites with the most fertile soil layer previously removed, with a thickness of 15$20 \mathrm{~cm}$. The removed and stored soil can be used for any recreational purposes, including for the restoration of alluvial maps after drying.

Erik dredging works are associated with the inevitable placement of bottom soils in adjacent territories.

In this regard, it is necessary to locate places of dumps or sedimentation maps of bottom sediments on vegetation free, requiring a long time for its restoration (trees, shrubs), places.

The bottom sediments are similar in their mechanical composition and organic matter content to soils, but contain slightly less toxic salts. Therefore, the placement of bottom sediments is permissible without preliminary preparation of the territory for their placement in the form of removal of the humus horizon and its subsequent return to the surface of the bottom sediment map, even in the case of simple digging of soil by excavators or grabs

When dredgers deepen, salinity indicators of bottom sediments improve due to their washing in the pulp.

With a ratio of the volumes of soil to water in the pulp of 1:10 for specific conditions, the mineralization of pulp water in the case of a maximum salt content in the bottom soil will be $(0.616 \times 15+0.346 \times 10): 10=1.27 \mathrm{~g} / \mathrm{dm}^{3}$.

Based on the conditions that during the drying period of the card, $1.0 \mathrm{~m}^{3}$ of soil $1.0 \mathrm{~m}^{3}$ of water can evaporate from it, the content of salts remaining in the soil will be $1270 \mathrm{~g}$, and the percentage of salts will be about $0.084 \%$. In the case of lower initial salt content salinity of washed soils will be even less. 
This allows harmonization of the island topography with the flooding of local depressions and the lowest places in the topography with initially saline soils.

For the fastest "start-up" of the soil-forming process, biological reclamation of the surfaces of alluvial maps is carried out by sowing local cereal grasses in winter sowing dates, which will contribute to the fastest restoration of disturbed equilibrium in the landscape.

Hypsometrically, the surface of the alluvial maps should be linked to its flooding at least once every 2-3 years. This will allow the continuous development of meadow vegetation on their surface, which in turn will improve the habitat of terrestrial fauna, and in years with a high water level, in high water, they can serve as spawning grounds.

The impact of dredging on the animal kingdom will primarily affect ichthyofauna. In this regard, the timing of dredging should be consistent with the fisheries protection organizations.

The impact of dredging on the near-water and terrestrial fauna during the execution of the work will be associated with disturbance factors from the presence of people and working equipment, which may cause temporary migration of individual species of birds and groups of mammals from the places of work and their spatial redistribution in the biotope. The work schedule should be planned in such a way as to minimize these processes, especially during incubation of eggs and the appearance of broods of water birds.

Dredging directly violates aquatic vegetation, but it should be borne in mind that it has the properties of intensive self-healing and an increase in distribution areas.

From the above it follows that the violation of natural processes during dredging will ultimately lead to an improvement in landscape characteristics: an increase in runoff volume will be accompanied by an improvement in sanitary indicators of the water, harmonization of the relief will affect the improvement of habitat conditions for terrestrial and near-water fauna. The depths achieved by the project will ensure the fulfillment of those tasks for which dredging will be carried out.

Proposals for a program of industrial environmental control over the nature of changes in all ecosystem components during construction and operation of an object.

To monitor the work of construction equipment and adherence to the technology of dredging, industrial and environmental monitoring is carried out, and to assess changes in the state of hydrological, hydrochemical, hydrobiological parameters of the aquatic environment, complex ship observations with sampling of water and bottom soil (environmental monitoring) are provided.

Proposals for the monitoring of dredging and environmental monitoring are based on the requirements of the following laws and regulations:

1. Water Code of the Russian Federation;

2. Law of the Russian Federation "On Environmental Protection";

3. Recommendations on the environmental support of investment and construction projects. - M., 1998;

4. SP 11-102-97. Environmental engineering surveys for construction. -M., 1997;

5. Instruction on the environmental justification of economic and other activities.

Environmental monitoring is a system of observation, assessment and prediction of environmental changes. Monitoring should be carried out for the following purposes:

1. Timely identification and forecasting of the development of negative processes that affect the environment, the development and implementation of measures to prevent the negative consequences of these processes;

2. Assessment of the effectiveness of environmental protection measures.

The objectives of environmental monitoring are:

1. Monitoring the physical and chemical processes taking place in the natural environment of the studied area during the construction period, monitoring environmental 
indicators at the locations of potential sources of exposure and areas of potential distribution;

2. Identification of negative processes in the study area due to construction activities, and the causes of their occurrence;

3. Development of measures aimed at preventing and reducing the negative impact of the construction process.

The need for environmental monitoring during the construction and operation of production facilities is determined by the current legislation of the Russian Federation and international obligations.

Observation Dates.

At the work sites, 3 ship surveys should be performed per year before the start of work, in the middle of the term and at the end of the dredging. If possible, the timing of observations at the same time should be combined at several sites..

Lots of observations.

It is proposed that environmental studies be carried out at each dredging site and in the area where underwater dumps are located.

Composition of observations.

Production and environmental control, should include the following types of work:

1. Check the completeness of documentation for dredging and alluvial work;

2. Assessment of conformity of the work performed to the project of work or terms of reference;

3. Determining the characteristics of the developed soils according to engineering and geological surveys and the project of work.

Local environmental monitoring.

Hydrometeorological observations should consist of the following observations:

1. Due to the characteristics of the atmosphere - temperature, humidity, atmospheric pressure, wind speed and direction, cloudiness, visibility, dangerous weather phenomena;

2. Due to the characteristics of the aquatic environment - temperature, salinity, speed and direction of currents, transparency and color of water, turbidity.

Hydrochemical observations. Should include river water sampling for analytical determination of the following indicators:

1. Dissolved oxygen;

2. $\mathrm{Ph}$;

3. Suspended substances;

4. Dry residue;

5. Salt composition;

6. BGK5;

7. Surfactants, phenols, petroleum products;

8. Heavy metals;

Geo-ecological monitoring. This consists in sampling bottom sediments in areas of dredging and in dumping areas to determine:

1. With a layered description - lithological composition, color of sediment, presence of inclusions, consistency;

2. In an analytical study - particle size distribution, chemical composition, radiation analysis.

Observations of the spread of the plume complementary to the background turbidity. Carrying out environmental monitoring, it is necessary to provide modeling of the transport and distribution of pollutants, during which output data will be obtained, including the following set of indicators:

1. Middle zones of pollution of the water column with suspended solids over the entire period of operation of the source of exposure, including water volumes and water 
surface areas susceptible to pollution with different gradations of concentrations of solid particles;

2. The maximum and average lifetime of threshold concentrations of suspended matter in a typical plume of suspended solids;

3. Characteristics of the plumes of suspended solids in the water column, including average and maximum lengths, as well as the lifetime of the plumes of pollutants with different gradations of concentrations;

4. Deposition zones at the bottom of the solid phase of pollutants, including the area of sediment zones with different sediment thicknesses, the maximum distances from the source of discharge to isolines with different sediment thicknesses;

5. The characteristic deposition of the solid phase of pollutants depending on the distance from the source of exposure.

Hydrobiological and ichthyological observations. The main tasks of monitoring aquatic biological resources must be:

1. Assessment of the state of primary biological and feed communities (phytoplankton, zooplankton, zoobenthos); assessment of the species composition, reproduction efficiency and productivity of generations of fish according to the state of ichthyoplankton in the water area according to the grid of monitoring stations;

2. Performing an accurate calculation of the size of the resulting damage to aquatic biological resources caused by hydraulic works.

Hydrobiological and ichthyological observations of aquatic biological resources include:

- background monitoring (assessment of the state of aquatic biota before the start of work);

1. monitoring at the production stage;

2. monitoring after completion of work.

The points of hydrobiological and ichthyological observations are combined in time and space with points of water sampling for the determination of hydrochemical parameters.

Planned list of observations at each stage:

1. General indicators:

2. Photosynthetic pigments (chlorophyll);

3. Primary production of plankton;

4. Destruction of organic matter;

5. Phytoplankton, zooplankton, macrozoobenthos:

6. Species composition;

7. Number;

8. Biomass of individual groups and total;

9. Indicator types;

10. Bacterioplankton: total abundance; saprophytic microflora; ichthyofauna (larvae, juveniles); species composition; strength

11. Biomass;

12. Degree of dominance; age structure.

The work on monitoring the state of aquatic biological resources, in addition to collecting and primary processing of materials in marine expeditions, includes: desk processing of field observation materials, mathematical processing of materials, preparation of reporting documentation. Sanitary and bacteriological observations.

Designed to characterize the sanitary state of water and man-made filler in the area of work and are associated with the study of samples for the following indicators:

1. For water-OKB, E.coli, coliphages, enterococci, staphylococci;

2. For soils - BGKP index, enterococcal index, pathogenic bacteria, helminth eggs. 
All chemical and analytical studies of environmental components must be carried out by laboratories accredited to the relevant types of analyzes.

The composition and frequency of the observations can be adjusted depending on the results.

The results of control measurements should be regularly reported to state regional specially authorized bodies in the field of environmental protection.

In the event that water areas with unfavorable environmental conditions, which overstate design indicators of water quality, are identified during the production process, measures must be taken to identify the causes of this situation and to eliminate them as soon as possible.

To conduct local environmental monitoring, the Observation Program must first be developed and agreed upon, taking into account the actually used dredging equipment and the general period of work.

\section{Conclusions}

In the process of measuring the depths as part of the engineering and hydrometeorological surveys, 4 surface water samples were taken, in which the salt composition, the content of heavy metals, phenols, oil products and ASAs were determined. The dissolved oxygen content was determined in a collection sample taken in the course of engineering geological surveys.

Dredging did not qualitatively affect the ecological state of the controlled facilities, since the content level of most of the determined indicators in the background and work areas did not exceed the maximum permissible standards, or did not differ much from the background. The spatial distribution of pollutants in the water and bottom sediments in the water area during this period does not allow us to identify individual pollution zones associated with dredging.

The studied environmental situation in the water area is stable. The quality of surface water and bottom sediments does not depend on the work performed, but is determined by the background component of the transit flow.

\section{References}

1. N. M. Ivanyutin, S. V. Podovalova, Wat. Eco., 4(76), 9-19 (2018) DOI:10.23968/2305-3488.2018.23.4.9-19.

2. Y. D. Smirnov, M. V. Suchkova, Wat. Eco., 3 (2017) DOI:10.23968/23053488.2017.21.3.35-48.

3. T. L. H. Nguyen, M. Ohtsubo, Y.L. Loreta, T. Higashi, M. Kanayama Paddy, Wat. Envir. 6, 257-262 (2008) DOI: 10.1007/ s10333-008-0125-y.

4. E. V. Mahanova, Wat. Eco. 2(78), 102-110 (2019) DOI: 10.23968/23053488.2019.24.2

5. T. Alemu, S. Bahrndorff, C. Pertoldi, K. Hundera, E. Alemayehu, A. Ambelu, Eco. Indic. 87, 77-85 (2018) DOI: 10.1016/j.ecolind.2017.12.032.

6. R. Capela, J. Raimundo, M. M. Santos, M. Caetano, C. Micaelo, C. Vale, L. Guimarães, M. A. Reis-Henriques, Sci. Tot. Envir. 539, 85-96 (2016) DOI: 10.1016/j.scitotenv.2015.08.113.

7. L.I. Cvetkova, G.I. Kopina, S.V. Makarova, S.V. Zajceva, O.I. Kabrgel, Wat. Eco. 2, 13-22 (2015) DOI:10.23968/2305-3488.2015.11.2.35-48.

8. R.N. Bubenov, V.I. Borisenko, A.A. Danilenko, L.A. Bubenova, S. of Russia: eco., 13, 147-156 (2018) DOI: 10.18470/1992-1098-2018-4-147-156 
9. M. Gharibreza, A. Nasrollahi, A. Afshar, A. Amini, H. Eisaei, CATENA E 166, 339348 (2018)

10. F. Culhane, H. Teixeira, A.J. A. Nogueira, F. Borgwardt, L. A. Robinson, Sci. Tot. Envir. 660, 611-621 (2019)

11. C. Shuhong, Z. Shijun, Z. Dianfan, Neurocomputing, 349, 301-313 (2019)

12. L. Bonadonna, R. Briancesco, G. La Rosa, Microchem. J. 150 (to be published)

13. P. Palma, L. Ledo, P. Alvarenga, Sci. Tot. Envir. 541, 119-129 (2016)

14. D. F. Langendoen, J. Lemly, W. Nichols, J. Rocchio, Eco. Indic. 104, 764-775 (2019)

15. N. Manap, N. Voulvoulis, J. Clean. Prod. 137, 394-404 (2016) 